Royal Netherlands Institute for Sea Research

This is a preprint of:

Haren, H. van \& Greinert, J. (2016). Turbulent high-latitude oceanic intrusions-details of non-smooth apparent isopycnal transport West of Svalbard. Ocean Dynamics, 66, 785-794

Published version: $\underline{\mathrm{dx} . \text { doi.org/10.1007/s10236-016-0955-x }}$

Link NIOZ Repository: $w w w . v l i z . b e / n l / i m i s ?$ module=ref\&refid=20259961

Article begins on next page]

The NIOZ Repository gives free access to the digital collection of the work of the Royal Netherlands Institute for Sea Research. This archive is managed according to the principles of the Open Access Movement, and the Open Archive Initiative. Each publication should be cited to its original source - please use the reference as presented.

When using parts of, or whole publications in your own work, permission from the author(s) or copyright holder(s) is always needed. 


\title{
Turbulent high-latitude oceanic intrusions - details of non-smooth apparent isopycnal transport West of Svalbard
}

\author{
by Hans van Haren ${ }^{a, *}$, Jens Greinert ${ }^{\text {b,c,d }}$
}

${ }^{a}$ NIOZ Royal Netherlands Institute for Sea Research and Utrecht University, P.O. Box 59, 1790 AB Den Burg, the Netherlands.

*e-mail: hans.van.haren@nioz.nl

${ }^{\mathrm{b}}$ GEOMAR Helmholtz Centre for Ocean Research Kiel Wischhofstrasse 1-3, 24148 Kiel, Germany. ${ }^{c}$ ChristianAlbrechts University, Institute of Geosciences, Ludewig-Meyn-Str. 10, 24118 Kiel, Germany.

${ }^{\mathrm{d}} \mathrm{CAGE}$ - Centre for Arctic Gas Hydrate, Environment and Climate, UiT The Arctic University of Norway, Tromsø, Norway. 


$\begin{array}{lll}37 & \text { Abstract } \\ 38 & \text { Filament intrusions are observed in high-resolution temperature (T-) measurements from a 100-m and } \\ 39 & \text { several months-long mooring in the Fram Strait around } 400 \mathrm{~m} \text { water depth at the continental slope } \\ 40 & \text { West of Svalbard (Spitsbergen, Norway). In this dynamic environment, a wide variety of intrusive } \\ 41 & \text { layers are observed with thicknesses between } 5 \text { and } 80 \mathrm{~m} \text { with warmer water between cooler waters } \\ 42 & \text { above and below. The layers typically last from several hours up to one day, exceeding the local } \\ 43 & \text { buoyancy period but not lasting as long as intrusive layers in the open ocean. The intrusions are a } \\ 44 & \text { result of an interminglement of Arctic and North-Atlantic waters and generated in the basins interior } \\ 45 & \text { and locally via internal wave steepening upon the sloping bottom. Freely propagating semidiurnal } \\ 46 & \text { lunar internal tides cannot exist without background vorticity at these high-latitudes. Strongly } \\ 47 & \text { nonlinear turbulent bores are not observed at the tidal periodicity, but wave fronts occur at the sub- } \\ 48 & \text { inertial frequency of dominant baroclinic instability. The fronts are in part associated with near- } \\ 49 & \text { buoyancy frequency internal waves (breaking). The details of the moored T-observations and their } \\ 50 & \text { spectral content demonstrate the non-smooth, relatively turbulent development including convective } \\ 51 & \text { overturning and shear-induced instabilities when intrusions disperse in presumably salinity- } \\ 52 & \text { compensated isopycnal layers. Some effects of this 'isopycnal mixing' or 'mixing while intruding' on } \\ 53 & \end{array}$

55 Keywords high-resolution temperature observations; West-Svalbard; poleward of critical 56 lunar tidal latitude; intrusions; high-frequency internal wave breaking; non-smooth isopycnal 57 dispersal 


\section{Introduction}

In the ocean, density compensation of temperature by salinity variations is often found in the vertically quasi-homogeneous 'mixed-layer' near the surface (e.g., Rudnick and Ferrari 1999). In deeper waters, density variations are generally dominated by temperature variations (Schmitt 1999), with exceptions, e.g., around the relatively warm and salty Mediterranean outflow lenses 'Meddies' in the North-Atlantic Ocean (Hebert et al. 1990; Ruddick 1992) and the relatively warm and salty NorthAtlantic waters colliding with Arctic waters around Spitsbergen (Perkin and Lewis 1984). In general, the associated filaments of intruding water with distinctly different characteristics than waters above and below can be followed across $100 \mathrm{~km}$ or more in the open ocean (May and Kelley 2001) or last for months (Hebert et al. 1990). This occurs in deep ocean waters as well as in shallow seas like the Baltic (Holtermann 2015). With the dispersing and eventually disappearing intrusions, other (conservative) suspended and soluble materials that further characterize the different water masses become integrated in the (Atlantic) ocean circulation.

For the main driver of these 'thermohaline intrusions', double diffusive fluxes have been suggested. As described by Turner (1979), a layer of warm and salty water may intrude at its particular density level in a stably density stratified ocean with relatively cooler and fresher characteristics due to salt finger diffusion at its lower edge and diffusive convection at its upper edge. This is because of the higher (molecular) diffusivity for heat compared with salinity, thus causing growing instabilities for the lower edge and restoring oscillatory motions for the upper edge. According to Ruddick (1984; 1992), the particular baroclinic instability generates different slopes of intrusions on either side of a front, initially separating two different water masses after equalizing (homogenizing) density differences.

As the turbulent mixing associated with the homogenization can be particularly large above sloping topography (Armi 1978), it has been suggested that there intrusions may largely transport mixed waters from the near-bottom 'boundary layers' into the ocean interior. Such topographyinduced intrusions are a plausible explanation for the generation of so-called 'nepheloid layers' of sediment whirled up from sloping bottoms and transported more or less along isopycnals into the 
interior (Cacchione and Drake 1986), but not necessarily above 'critical slopes for internal tidal waves' (Hosegood and van Haren 2004; the present data).

Here, we hypothesize that these layers extending from sloping topography must be different from 'water mass intrusions' associated with e.g. Meddies. This is because the main turbulent mixing agent above sloping topography is the breaking of baroclinic ('internal') waves, generally through bores occurring once or twice at the dominant tidal, inertial but also sub-inertial periodicities (Hosegood and van Haren 2004). The highly nonlinearly deformed waves transforming into upslope propagating bores induce so much turbulent mixing that is estimated by van Haren and Gostiaux (2012) to be sufficient to maintain the ocean interior stratified as it governs the transport of heat downwards (Munk 1966). Although the sloping topography induces rapid re-stratification, after the turbulent overturning, and to within about a meter from the bottom, the thus effective mixing is expected to also destroy intrusions by homogenizing the near-bottom region periodically for brief moments. Associated intrusions are not thought to exist longer than, e.g., a tidal period. This hypothesis is investigated in a study that also aims to reveal in some detail the character of intrusions.

For this purpose, high-resolution temperature sensors were moored for a year above the continental slope on the east side of the arctic Fram Strait, in an area where-also methane seeps are active. Similar observations have been made in the Southern Ocean in $950 \mathrm{~m}$ water depth at the continental slope off New Zealand (van Haren and Greinert 2013). There, 20-50 m thick temperature inversions were observed persistent for 1-24 h, but the recorded data set was rather short in time ( 9 days) for extensive study of the origin of the intrusions. The observations offshore New Zealand were made in an area of active methane seepage with gas bubble release to investigate if such release has a measurable impact on the ocean stratification. Although gas release was found in the area, the turbulent mixing was not due to bubble rising effects but could be related to sloping boundary layer effects as large internal wave breaking through nonlinear bores was observed. Such wave breaking may lead to intrusions, as is investigated here.

Intrusions are easily detected in moored thermistor string data when their duration surpasses that of the local buoyancy period. As no moorable salinity sensors were available, quantification of turbulence parameter estimates cannot be made when intrusions are regularly present. 


\section{Materials, background conditions and methods}

A taut-wire mooring was deployed from 25 July 2012 to 16 July 2013 at the continental slope

West of Svalbard (Spitsbergen, Norway; Fig. 1). Its position was $78^{\circ} 37.09^{\prime} \mathrm{N}, 9^{\circ} 19.00^{\prime} \mathrm{E}, \mathrm{H}=450 \mathrm{~m}$ water depth. It was thus about $4^{\circ}$ poleward of the latitude at which the local inertial frequency 'critically' matches the semidiurnal lunar tidal frequency $\mathrm{M}_{2}$. As a result, no freely propagating internal waves at the dominant tidal frequency can exist at the present mooring site without the aid of negative relative vorticity, e.g., generated by mesoscale eddies. Internal tides, if existent, thus vary between trapped and propagating modes at sub-inertial periodicities.

A total of 100 'NIOZ4' self-contained temperature (T) sensors were taped at $1.0 \mathrm{~m}$ vertical intervals to a nylon-coated steel cable, with the lowest sensor $6.4 \mathrm{~m}$ above the bottom and the upper about $2.5 \mathrm{~m}$ below a single elliptic floatation providing $2000 \mathrm{~N}$ of net buoyancy. NIOZ4 is an upgrade of NIOZ3 (van Haren et al. 2009), with similar characteristics, except for its reduced size (2/3 smaller). The sensors sampled at a rate of $1 \mathrm{~Hz}$, with precision better than $0.001^{\circ} \mathrm{C}$ and a noise level of about $6 \times 10^{-5 \circ} \mathrm{C}$. They were synchronized to a standard clock via induction every $6 \mathrm{~h}$, so that the timing mismatch was less than $0.04 \mathrm{~s}$. Due to battery problems, only half of the sensors completed the one year record of the duration of the mooring. Here, the focus is on the first 100 days when most sensors were operational.

No current meters were moored and we have to refer to previous current observations (e.g., Kasajima and Svendsen 2002; Teigen et al. 2011). From the historic observations obtained in the vicinity of our mooring site it is learned that currents are largely barotropic, with little phase shifts in the vertical, especially for diurnal and semidiurnal tides (station F, Fig. 2 in Kasajima and Svendsen 2002). The semidiurnal current is mainly directed along the shelf (Teigen et al. 2011). Largest currents are found at sub-inertial frequencies, due to meanders or eddies (Schauer et al. 2004) that are considered generated through 35-75 h baroclinic instabilities slightly off-shelf (Teigen et al. 2011).

During the mooring handling cruises, shipborne SeaBird-9plus Conductivity-Temperature-Depth (CTD) data were obtained within $1 \mathrm{~km}$ from the mooring site. These data are used to establish the 
temperature-density relationship around the depth of the moored temperature sensors. Data from the

143 latter are first transferred to Conservative Temperature $(\Theta)$ values (IOC, SCOR, IAPSO, 2010), 144 before they are used as an estimate for (variations in) potential density anomaly referenced to a level 145 of $400 \mathrm{dBar}\left(\sigma_{0.4}\right)$ following a not very tight, constant linear relationship obtained from CTD data 146 (Figure 2), $\delta \sigma_{0.4}=\alpha \delta \Theta, \alpha=-0.067 \pm 0.01 \mathrm{~kg} \mathrm{~m}^{-3{ }^{\circ}} \mathrm{C}^{-1}$ denoting the thermal expansion coefficient under 147 local conditions. This relationship is the mean for the lower $150 \mathrm{~m}$ of the CTD-profile.

Like turbulence parameter estimates, local values for buoyancy frequency $\mathrm{N}$ can also not be established as reordering the moored temperature (density) profiles in statically stable ones has no meaning when (numerous) intrusions are present. Only a sufficiently long and full-vertical-range mean $\mathrm{N}$-value can be estimated using the present data, and which is compared with $\mathrm{N}$ from CTD-data.

\section{Observations}

\subsection{Overview}

Hydrographically, the CTD-data from the single station at $1 \mathrm{~km}$ to the southwest of the mooring show that between 50 and $250 \mathrm{~m}$ temperature dominates over salinity contributions to density (Fig. 3a-c). Even in this layer small intrusions do occur, e.g. near $-170 \mathrm{~m}$. Above this layer, in the upper 20 $\mathrm{m}$ from the surface, the water is more or less well mixed and relatively low in salinity. Below this well-mixed surface layer down to about $400 \mathrm{~m}$, temperature and salinity roughly compensate each other, although temperature variations still gain so that density is stably stratified. A range of about 50 $\mathrm{m}$ above the bottom is near-homogeneous albeit with weakly stratified portions, in this CTD-profile. As will be shown below, this near-bottom range varies strongly with time. Over a five day period, the mean Conservative Temperature change over a $100 \mathrm{~m}$ vertical range (of the moored T-sensors) amounts to $0.36^{\circ} \mathrm{C}$, which gives a mean 'large-scale' buoyancy frequency of $\mathrm{N}=1.6 \times 10^{-3} \mathrm{~s}^{-1}(\approx 22$ cycles per day, cpd) using the temperature-density relationship in Fig. 2. This $\mathrm{N}$-value closely corresponds with the mean buoyancy frequency of $\simeq 20 \mathrm{cpd}$ computed for the same $100 \mathrm{~m}$ range from the CTD-profile in Fig. 3d. This gives an approximate mean buoyancy period of $T_{N}=2 \pi / N=4000 \mathrm{~s}$. 
During the first 43 days of the record in mid-summer, no long periods of salinity compensation seem to exist (Fig. 4a). The overview impression is a generally stable stratification in temperature with relatively warmer waters above cooler waters, and some clear exceptions like around day 235 . Over time, $2-5 \mathrm{~d}$ periodically alternating bands of warmer and cooler waters are observed that are, roughly, uniform in the vertical. In the lower $50 \mathrm{~m}$ above the bottom, transitions ('fronts') are visible from relatively warm to cooler waters, e.g. on days $213,218,222,224,228, \ldots$ Their primary periodicity is thus also some 2-5 d, as observed previously in the Faroe-Shetland Channel (Hosegood and van Haren 2004). Spectra from three different depth levels show no distinct peaks, with largest variance around the sub-inertial frequency $\mathrm{I}_{\mathrm{bc}} \approx 0.33 \mathrm{cpd}$ (Fig. $4 \mathrm{~b}$ ). The latter is named after the baroclinic instability modelled by Teigen et al. (2011), and apparently also dominates the appearance of temperature fronts here.

Temperature shows no peak around the semidiurnal inertial/tidal band (Fig. 4b). From left to right in this band, main harmonic spectral peaks are expected in the raw periodogram at $\mathrm{M}_{2}$, the lunar tidal component, $f$, the inertial frequency, and $\mathrm{S}_{2}$, the solar tidal component. However, none are observed (not shown). We have no information on the local background vorticity, which is assumed zero here. On average, the lunar semidiurnal tidal component is thus outside the band of freely propagating internal gravity waves $\mathrm{f}<\sigma<\mathrm{N}$, under moderate-strong stratification. However, the entire spectrum is featureless with the lowest energy close to the bottom (blue spectrum) and a more or less constant slope in frequency of $\sigma^{-2}$ for $\sigma>13 \mathrm{cpd}=0.6 \mathrm{~N}$. For about $(0.5-1) \mathrm{f}<\sigma<0.5 \mathrm{~N}$, the spectra roughly slope like $\sigma^{-1}$, also for the blue spectrum. Note that the latter changes to a slope of $\sigma^{-3}$ at about $0.2 \mathrm{~N}=$ $4.5 \mathrm{cpd}$, half the local (near-bottom) buoyancy frequency (cf, Fig. 3d).

These changes in slope are indicative of a peak in the internal wave's vertical current spectrum of an open ocean internal wave field under sufficient stratification (van Haren 2015). The observed $\sigma^{-2}$ slope for $\sigma>\mathrm{N}$ into the turbulence band also indicates fine-structure contamination. Accidently, the extent of this $\sigma^{-2}$-slope, both in frequency and variance ranges, and the transition to a weaker $\sigma^{-1}$-slope can also be inferred in current meter spectra of Kasajima and Svendsen (2002; their Fig. 2). In fact, of all their seven mooring positions across Fram Strait, the one (station F) nearest to our mooring site 
197

shows largest 'background' spectral levels. This implies locally relatively high internal wave and 196 turbulence variance levels.

\subsection{Detailed moored observations}

During detailed investigations, many large and thin layers were observed of which a nonexhaustive selection is presented in this Section. In each of the figures, the mean buoyancy period of $4000 \mathrm{~s}$ is indicated by a purple bar. The colour range is fixed for each figure, but changes are made between the figures for displaying clarity since the mean values vary considerably (cf. Fig. 4a). Isotherm contours are drawn in black; each colour range is divided in 10 equidistant isotherms. Thus, with the varying temperature range, the temperature interval also changes between figures. The ruggedness of isotherms may be used as a qualitative indicator for vertical (diapycnal) turbulent exchange: the more rugged, the more turbulent.

The first example shows intrusions, some of which in relatively strong stratification during a general cooling phase of upslope motions (Fig. 5a). The cooler waters from below push the warmer waters up in a not very sharp, but nonetheless turbulent front, or multiple fronts, around day 214.1. Besides the large near-homogeneous layer to the left off the bottom (orange), substantial intrusions are found near the interface (between red and blue). The rightmost intrusion is about 1.2 times longer than the mean buoyancy period. The central intrusion is observed over approximately one buoyancy period. Assuming that we are dealing with a cold intrusion in a warmer environment, its detail (Fig. $5 b)$ shows rugged isotherms between the relatively warm (red) waters above and cooler water in the intrusion. This interface would correspond to finger-formation in terms of double diffusion. The interface $5 \mathrm{~m}$ below is less rugged, especially in the first half of the period displayed. In terms of double diffusion, this would correspond to a diffusive flux layer. Note that the lower/deeper side of the thin, relatively warm layer below shows very smooth isotherms (the steppiness in the colours reflects the sensor separation of $1 \mathrm{~m}$, which poorly resolves the thinner interface). This calm, weakly turbulent layer delineates a high-frequency quasi-solitary internal wave (dipping at day 214.115). The somewhat deformed yellow layer $10 \mathrm{~m}$ below and dipping at day 214.116 seems to become overturned through shear as it is followed $900 \mathrm{~s}$ later by a layer in a clearer overturning stage. On a 
smaller scale, such near-overturning is visible close to the arrow in the rugged part of the intrusion, again suggesting shear-induced turbulence.

Also in the warming downslope phase thin $(<10 \mathrm{~m})$ and thick $(>50 \mathrm{~m})$ layers are observed (Fig. 6a). Around day 222.65 , a thin warm intrusion is observed separating two cooler water layers of which the colder one (above-left) extends from the near-bottom steeply upward. The upper edge of this thin intrusion is sharply delineated and has the more rugged appearance including small-scale billow-like overturns (Fig. 6b). This is the expected diffusive side of the intrusion. The lower, fingertype side shows smoother isotherms initially up to day 222.65. Later in time, but especially also deeper, more rugged isotherms show larger excursions somehow resembling convective type turbulence. On the large vertical scale of $20-40 \mathrm{~m}$, convective turbulence is observed under a warm descending layer (Fig. 6c). The finger-like turbulence alternate every $\sim 1000 \mathrm{~s}$, and continue in an intrusion around day 223.16. The latter intrusion has a duration that is just shorter than the mean buoyancy period.

A more prolonged warm intrusion (Fig. 7a), extending for a day, shows opposite isotherm ruggedness to the one described above: smooth isotherms on its upper, diffusive side, and rugged isotherms on its lower finger side (Fig. 7b). However, the lower side fingers are combined with the presence of Kelvin-Helmholtz (KH) shear-driven overturns, e.g. around days 224.45 and 224.475.

Clearer than in Figs $5 \mathrm{~b}$ and $6 \mathrm{~b}$, this $10 \mathrm{~m}$ thick intrusion shows blobs or patches of warmer water in its core occurring roughly every 500-1000 s around the highest displacement from the bottom. With them, the intrusion describes a wavy pattern, with a $1000 \mathrm{~s}$ periodicity. The following cooling phase shows barely a bottom front, but a cold 'front-intrusion' some distance off the seafloor, with rugged isotherms near its lower, diffusive border and smooth isotherms overturning in KH-billows around $400 \mathrm{~m}$ water depth (day 225.29 in Fig. 7c). This intrusion is also of longer duration than the mean buoyancy scale.

A $2.5 \mathrm{~h}$ long and wavy filament of warm intrusion is found extending from relatively warm waters into weakly stratified cooler waters, before turbulently ending in (sheared?) currents. This is shown in Figure 8, just prior to the arrival of an intrusive blob of warmer water around day 226.1. The 'front' around day 225.95 from which the filament intrudes is similar to the one in Fig. 7c, with more 
251

rugged isotherms near the lower border of the cold water (intrusion) and smoother isotherms showing occasional KH-billow overturning near its upper border. The warm intrusion filament (Fig. 8c), similar to the lower border of a front like in Fig. 7c but with the coldest water below, shows fairly smooth isotherms on the upper and lower side, until it starts widening from day 226.03 onward. The upper side waves with a $2000 \mathrm{~s}$ period, while the lower side has shorter periods between $400-500 \mathrm{~s}$ (indicated by the arrow). That side is more (finger, convective) turbulent too, and seems to dissolve the entire intrusion within an hour after day 226.055.

An example of longer lived, larger-scale (>50 m) warm intrusion (with thin cold intrusions inside) 259 is shown in Fig. 9. The intrusion is observed for about a day, and ends around day 236.0 with an 260 apparent front upside down as cooler water moves in from above driven by the following warm 261 waters. This second warm blob also has a relatively thick ( $>50 \mathrm{~m}$ ) cold intrusion around day 236.35 . 262 The large intrusions are characterized by abundant high-frequency internal waves with periods close 
propagating internal waves. They adopt a nonlinear shape and disintegrate rapidly. Although isotherms above and below are fairly smooth and intrusions are hardly visible, multiple billow-form overturns and sudden nonlinear peak-like waveforms are observed, indicative of convection. The third (right arrow in Fig. 10a) shows smooth small-scale waves observed at the transition from the cooling, upslope to the warming downslope phase (Fig. 10d). Waves having typically $1500 \mathrm{~s}$ period, commensurate the local small-scale buoyancy period, also deform a warm intrusion. The latter has very smooth isotherms with shorter scale anomalous temperature (intensity) variations. This resembles much more persistent (for days-weeks) open-ocean observations dominated by larger-scale and linear internal waves (cf. van Haren and Gostiaux 2009). Here, the isotherms surrounding the 40 m thick wave-layer show occasional KH-billow overturning (e.g., day 308.34, z = -390 m). The train of waves does not exceed 10 wave periods, in contrast with open-ocean observations.

An example of upslope moving bore associated with a large-scale $\mathrm{N}$-internal wave is given in Fig. 11. The about $60 \mathrm{~m}$ high overturning shows similarities with a frontal overturn observed in the tidally dominated methane seep area off New Zealand (van Haren and Greinert 2013): it is identical in height and overturning activity, but it is spread here over a range in time twice as long commensurate the doubling of the buoyancy period. Part of the cold front intrusions may have been formed non-locally, away from the front. The observed frontal wave motions extend to $100 \mathrm{~m}$ above the bottom, followed by a layer of intense turbulence also affecting the main pycnocline around $\mathrm{z}=-380 \mathrm{~m}$ that is found to widen with time.

\section{Discussion}

The present observations show that above a continental slope intrusions are relatively short-lived. They have durations of maximum a day, more typical a few hours or once-twice the large-scale mean buoyancy period. As this is much shorter than the weeks-months lifetime of intrusions in the open ocean reported previously (e.g., Hebert et al. 1990), nearby boundary effects are expected to be important for the apparent rapid dispersal of intrusions. 
long open-ocean observations around the depth of the lower edge of Mediterranean outflow water in the Canary Basin, van Haren and Gostiaux (2009) found intrusions that were persistent for weeks in the smooth internal waves. However, the intrusions' intensity varied over much shorter time scales of a few hours to a day. The latter duration is precisely as observed here, while the former is not present in our data. This implies that the stronger turbulence (on average by a factor of 100 in a tidedominated area; van Haren and Gostiaux 2012) above topography compared with the open ocean reduces the life-time of intrusions to a day or less.

Intrusions are suggested to be generated locally, e.g., at fronts between downslope moving warmer and upslope moving cooler waters. Such 'cold-front-generated' intrusions occur at sub-inertial timescales, the main current periodicity here, in the absence of strong tides. The fronts are varyingly associated with local small-scale near-buoyancy period internal waves, the naturally generated motion in a stratified fluid upon any forcing, their deformation and eventual breaking. In addition, interiorgenerated intrusions are observed to reach the topography from above and mix, typically within a day. The small-scale blobs of $<1 \mathrm{~h}$ duration (up to the large-scale buoyancy period) inside intrusions are also expected being generated by the turbulent processes near the topography.

Another effect of the internal wave breaking is the abundant generation of shear-induced K-H billows and convective overturning. This is observed in the loci of rugged and smooth isotherms, which are found highly variable above and below intrusions thus not reflecting fixed double diffusion processes. These findings confirm previous microstructure profiler observations from the Yermak Plateau north of Spitsbergen (Padman and Dillon 1991). In their measurements strong turbulence was also found in partially salinity-compensated 'quasi-intrusions'.

Although the present observations are from the Arctic region West of Spitsbergen, where dominant freely propagating internal tides do not exist, they may be used as examples for other areas where different water masses are mixed above topography. The appearance of turbulence in most of the intrusions compared to an open ocean setting suggest a rapid water mass mixing. In the present area, the precise time-scale and level of turbulence of this mixing of intrusions should be established 332 through microstructure profiler measurements. 
Originally, the mooring deployment was also planned to study enhanced mixing processes close to the seafloor occur. We speculated that methane-charged bottom water in the seep area around $400 \mathrm{~m}$ water depth (Westbrook et al. 2009; Sahling et al. 2014) might be transported higher up into the water 


\section{References}

Armi L (1978) Some evidence for boundary mixing in the deep ocean. J Geophys Res 83:1971-1979

Cacchione DA, Drake DE (1986) Nepheloid layers and internal waves over continental shelves and slopes. Geo-Mar Lett 16:147-152

Gentz T, Damm E, Schneider von Deimling J, Mau S, McGinnis DF, Schlüter M (2014) A water column study of methane around gas flares located at the West Spitsbergen continental margin. Cont Shelf Res 72:107-118

Hebert D, Oakey N, Ruddick B (1990) Evolution of a Mediterranean salt lens: scalar properties. J Phys Oceanogr 20:1468-1483

Holtermann P (2015) Ventilation of the Baltic Sea by lateral intrusions of water masses. $26^{\text {th }}$ IUGG General Assembly, Praha Cz 22 June-02 July

Hosegood P, van Haren H (2004) Near-bed solibores over the continental slope in the FaeroeShetland Channel. Deep-Sea Res II 51:2943-2971

IOC, SCOR, IAPSO (2010) The international thermodynamic equation of seawater - 2010: Calculation and use of thermodynamic properties. Intergovernmental Oceanographic Commission, Manuals and Guides No. 56, UNESCO (English) 196 pp

Kasajima Y, Svendsen H (2002) Tidal features in the Fram Strait. Cont. Shelf Res 22:2461-2477

May BD, Kelley DE (2001) Growth and steady state stages of thermohaline intrusions in the Arctic Ocean. J Geophys Res 106:16783-16794

Munk WH (1966) Abyssal recipes. Deep-Sea Res 13:707-730

Padman L, Dillon TM (1991) Turbulent mixing near the Yermak Plateau during the Coordinated Eastern Arctic Experiment. J Geophys Res 96:4769-4782

Perkin RG, Lewis EL (1984) Mixing in the West Spitsbergen Current. J Phys Oceanogr 14:1315-1325

Ruddick B (1984) A practical indicator of the stability of the water column to double-diffusive activity. Deep-Sea Res A 30:1105-1107 
Ruddick B (1992) Intrusive mixing in a Mediterranean salt lens: Intrusion slopes and dynamical mechanisms. J Phys Oceanogr 22:1274-1285

Rudnick DL, Ferrari R (1999) Compensation of horizontal temperature and salinity gradients in the ocean mixed layer. Science 283:526-529

Sahling H, et al. (2014) Gas emissions at the continental margin west off Svalbard: mapping, sampling, and quantification. Biogeosci 11:7189-7234.

Schauer U, Fahrbach E, Østerhus S, Rohardt G (2004) Arctic warming through the Fram Strait: Oceanic heat transport from 3 years of measurements. J Geophys Res 109:C06026, doi:10.1029/2003JC001823

Schmitt RW (1999) Spice and the demon. Science 283:498-499

Steinle L, et al. (2015). Water column methanotrophy controlled by a rapid oceanographic switch. Nature Geosci 8:378-382, DOI: 10.1038/NGEO2420

Teigen SH, Nilsen F, Skogseth R, Gjevik B, Beszczynska-Möller A (2011) Baroclinic instability in the West Spitsbergen Current. J Geophys Res 116:C07012, doi:10.1029/2011JC006974

Turner JS (1979) Buoyancy effects in fluids. Cambridge University Press 368 pp

van Haren H (2015) A composite vertical current spectrum for strongly and weakly stratified seas and oceans. J Mar Res 73:33-48

van Haren H, Gostiaux L (2009) High-resolution open-ocean temperature spectra. J Geophys Res 114:C05005, doi:10.1029/2008JC004967

van Haren H, Gostiaux L (2012). Detailed internal wave mixing observed above a deep-ocean slope. J Mar Res $70: 173-197$

van Haren H, Greinert J (2013) Variability of internal frontal bore breaking above Opouawe Bank methane seep area (New Zealand). Geochem Geophys Geosys 14:2460-2473, doi:10.1002/ggge.20170

van Haren H, Laan M, Buijsman D-J, Gostiaux L, Smit MG, Keijzer E (2009) NIOZ3: independent temperature sensors sampling yearlong data at a rate of 1 Hz. IEEE J Ocean Eng 34:315-322 
Westbrook GK, et al. (2009) Escape of methane gas from the seabed along the West Spitsbergen 2404 continental margin. Geophys Res Lett 36:L15608, doi:10.1029/2009GL039191. 
Fig. 1. Svalbard with mooring location indicated by the red dot. The nearest CTD location was $1 \mathrm{~km}$ to the SW of the mooring.

Fig. 2. Temperature-density relationship from CTD-observations for the lower $150 \mathrm{~m}$ above the bottom, at $1 \mathrm{~km}$ to the $\mathrm{SW}$ of the mooring. The linear best-fit is given (see text).

Fig. 3. CTD observations made shortly before mooring recovery, at a site $1 \mathrm{~km}$ to the $\mathrm{SW}$ and slightly deeper than the mooring. (a) Density anomaly, referenced to $400 \mathrm{~m}$. (b) Conservative temperature. The vertical bar indicates the range of moored temperature sensors. (c) Absolute salinity. The xaxis scale is similar to the temperature-scale in panel $b$ in the sense of equivalent contribution to density variations. (d) Buoyancy frequency, averaged over $10 \mathrm{~m}$ vertical intervals. The vertical dashed line indicates the average $\mathrm{N}$-value estimated from mean moored temperature observations using the temperature-density relationship from Fig. 2 .

Fig. 4. Overview of the first 43 days of moored high-resolution temperature sensor observations above the continental slope West of Svalbard. (a) Time-depth series of Conservative Temperature. (b) Spectra of the upper, middle and lowest sensors, weakly smoothed to provide approximately 15 degrees of freedom. The local mean buoyancy frequency is indicated together with its approximate spread (cf., Fig. 3d). Three spectral slopes $\sigma^{-\mathrm{x}}, \mathrm{x}=1,2,3$ are indicated (see text). $\mathrm{I}_{\mathrm{bc}}$ indicates the central frequency for topographic baroclinic instabilities modelled by Teigen et al. (2011).

Fig. 5. Example of detail observations of intrusions in a relatively strongly stratified layer. Ten black contours are drawn, equally distributed over the displayed temperature range. The purple bar indicates the duration of one mean buoyancy period of 4000 s. (a) Six hour time-depth series of Conservative Temperature. (b) One-hour detail zoom near arrow in a.

Fig. 6. As Fig. 5, but for intrusions in near-homogeneous layers. Note the different temperature range, and hence the different interval between temperature-contours. (a) Thirty hour time-depth series of 
Conservative Temperature. (b) One-and-a-half hour detail of thin layer intrusion near left arrow in

a. (c) Three-and-a-half hour detail of finger-like convection and thick layer intrusion around right

438 440

Fig. 7. As Fig. 5, but for a long, relatively thin intrusion in near-homogeneous waters. Note the

Fig. 11. As Fig. 5, but for large-scale buoyancy period wave upon a cold front in $7 \mathrm{~h}$ and $4000 \mathrm{~s}$ (length purple bar) panels. Note the change in colour, time and depth ranges.

Fig. 8. As Fig. 5, but for long-thin filament and larger-scale 'blob' intrusions in near-homogeneous waters. Note the slightly different temperature range. (a) Eight hour time-depth series of Conservative Temperature. (b) Forty minute detail of 'quasi-front' intrusion near arrow in a. (c) Two hour detail of thin filament with high-frequency internal wave oscillation having half-hour periodicity around day 226.04 .

Fig. 9. As Fig. 5, but for twenty-nine hour time-depth series of Conservative Temperature showing an example of a thick-layer intrusion(orange area) with thin-layers inside and bottom fronts with highfrequency internal waves, and a slant intrusion (blue area) with Kelvin-Helmholtz billows near the arrow. Note the different temperature range.

Fig. 10. As Fig. 5, but for fronts and intrusions in late fall with three 3 hour detail panels. Note the different temperature range. (a) Two day time-depth overview of Conservative Temperature. (b) Turbulent intrusion near left arrow in a. (c) After bottom-front passage with high-frequency internal waves having 30-15 min periodicity near middle arrow in a. (d) Around change into the warming phase with high-frequency internal waves having 25 min periodicity near right arrow in a. 


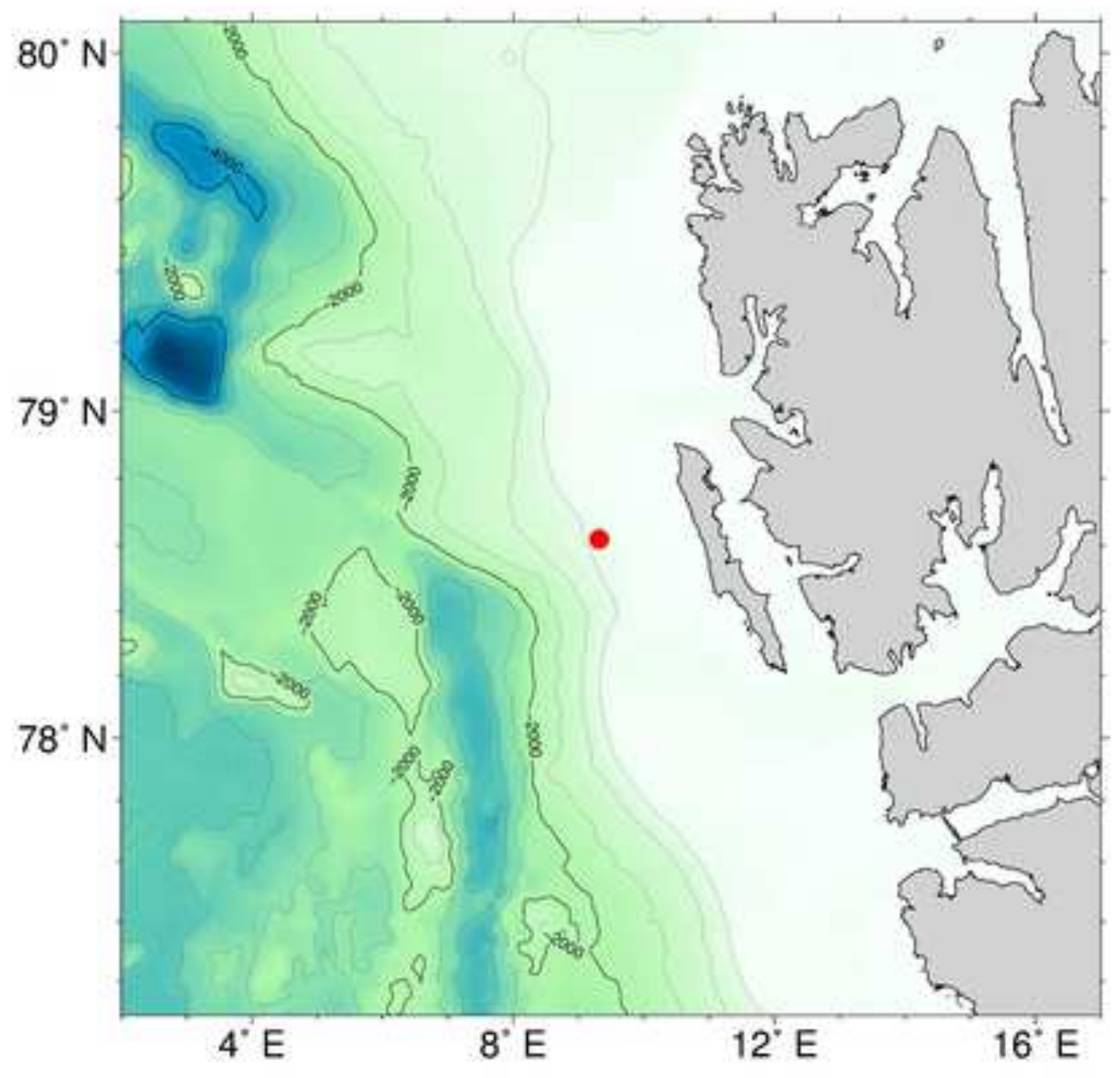

57

58

59

60

61

62 


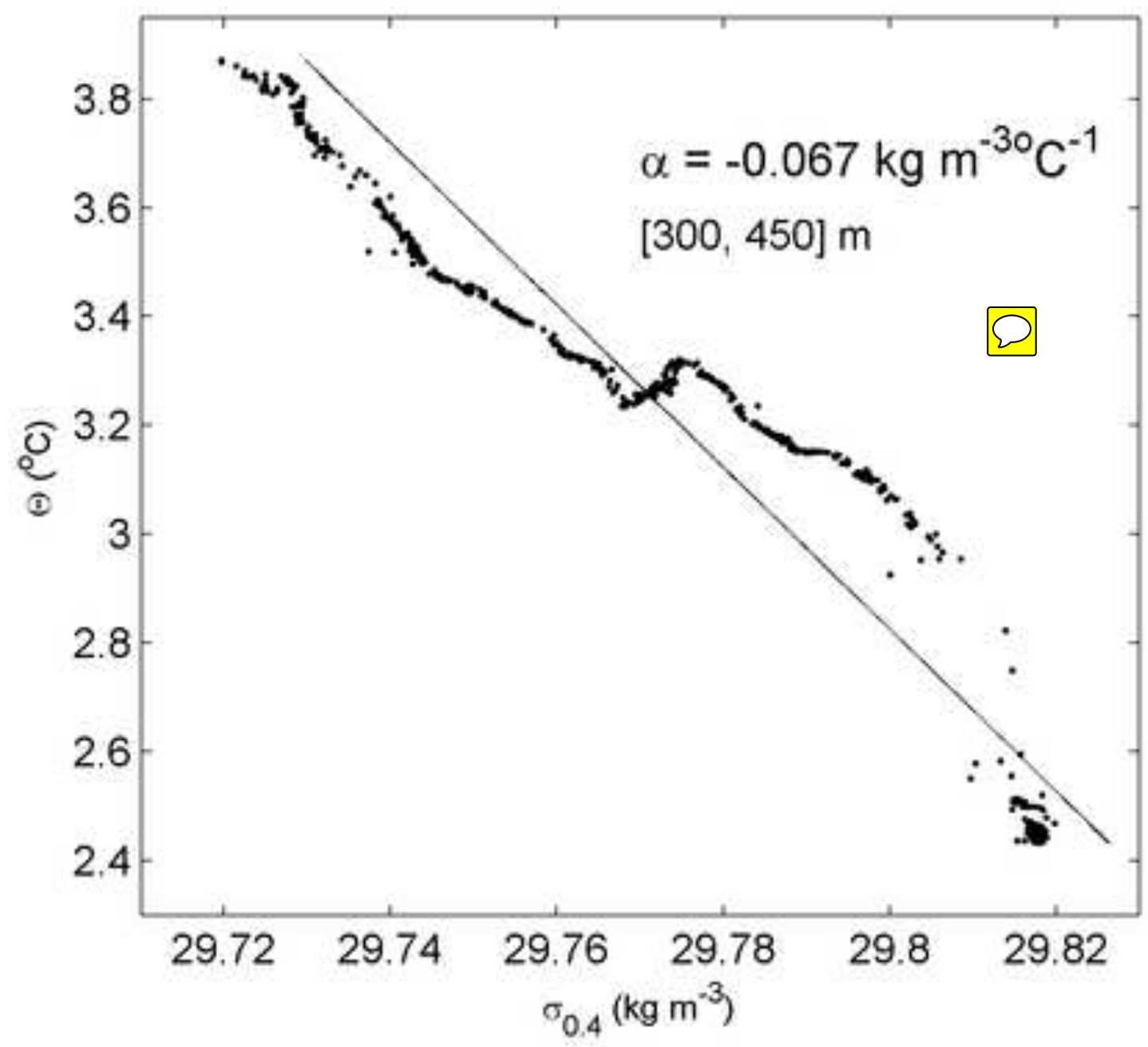




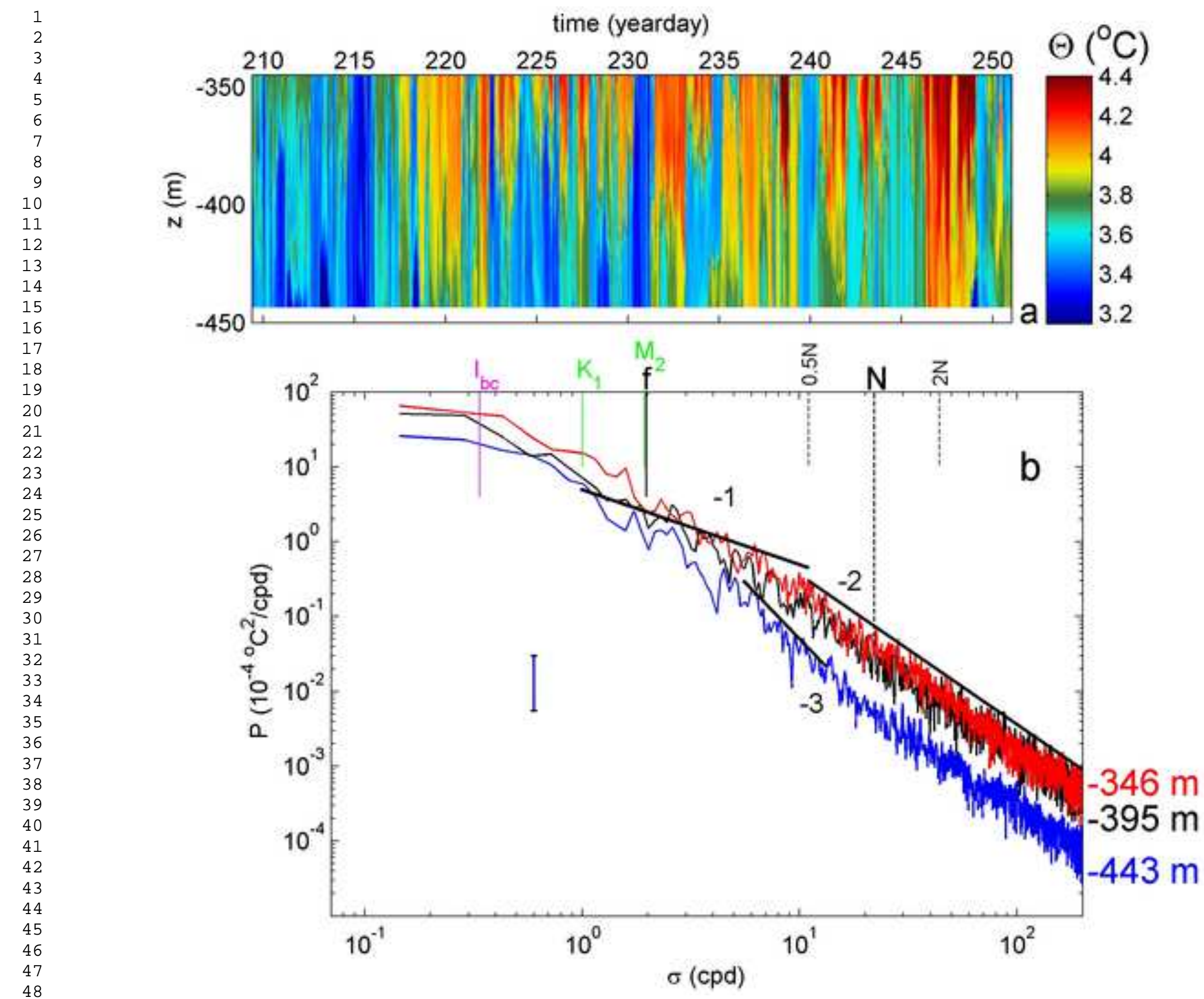



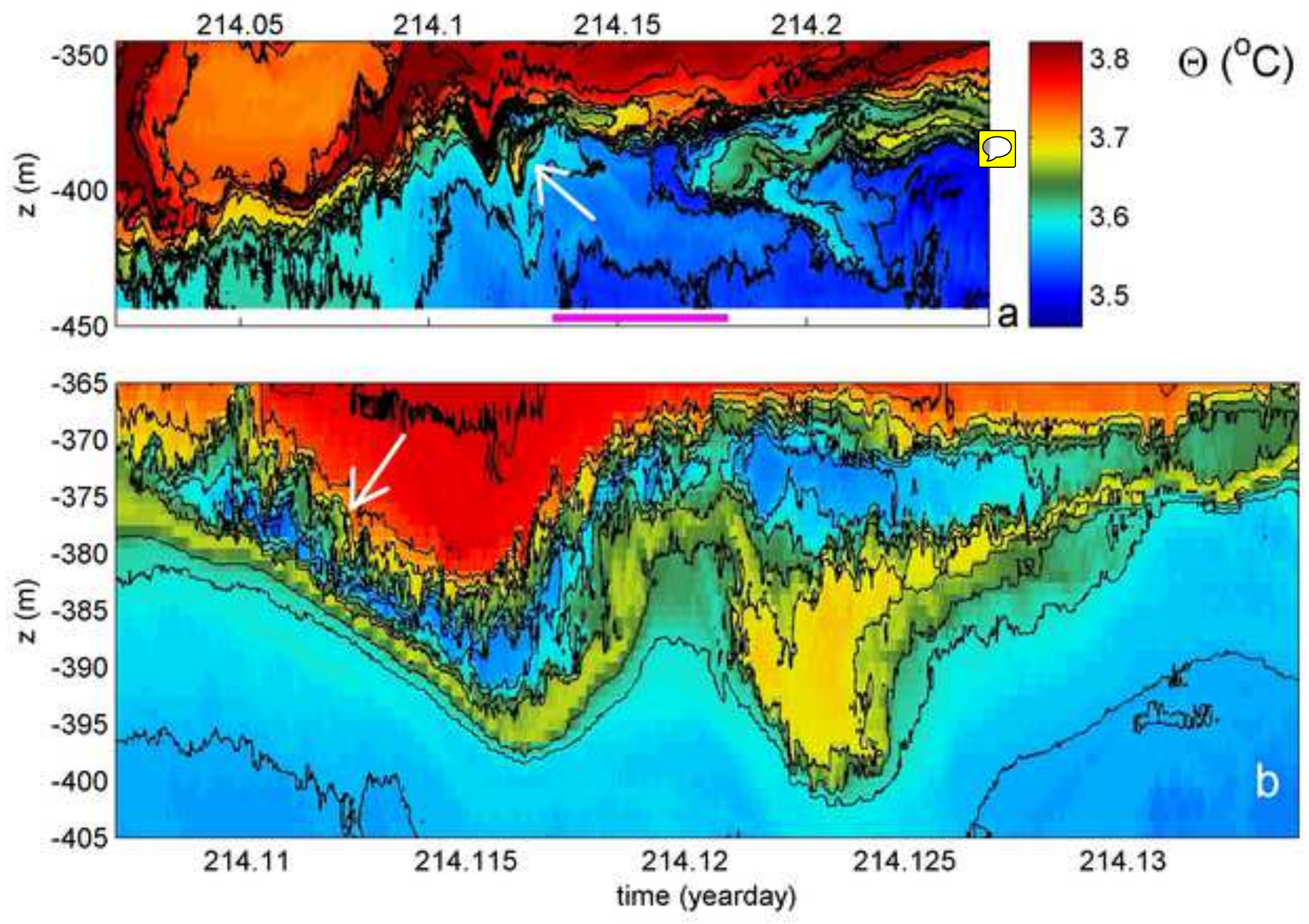

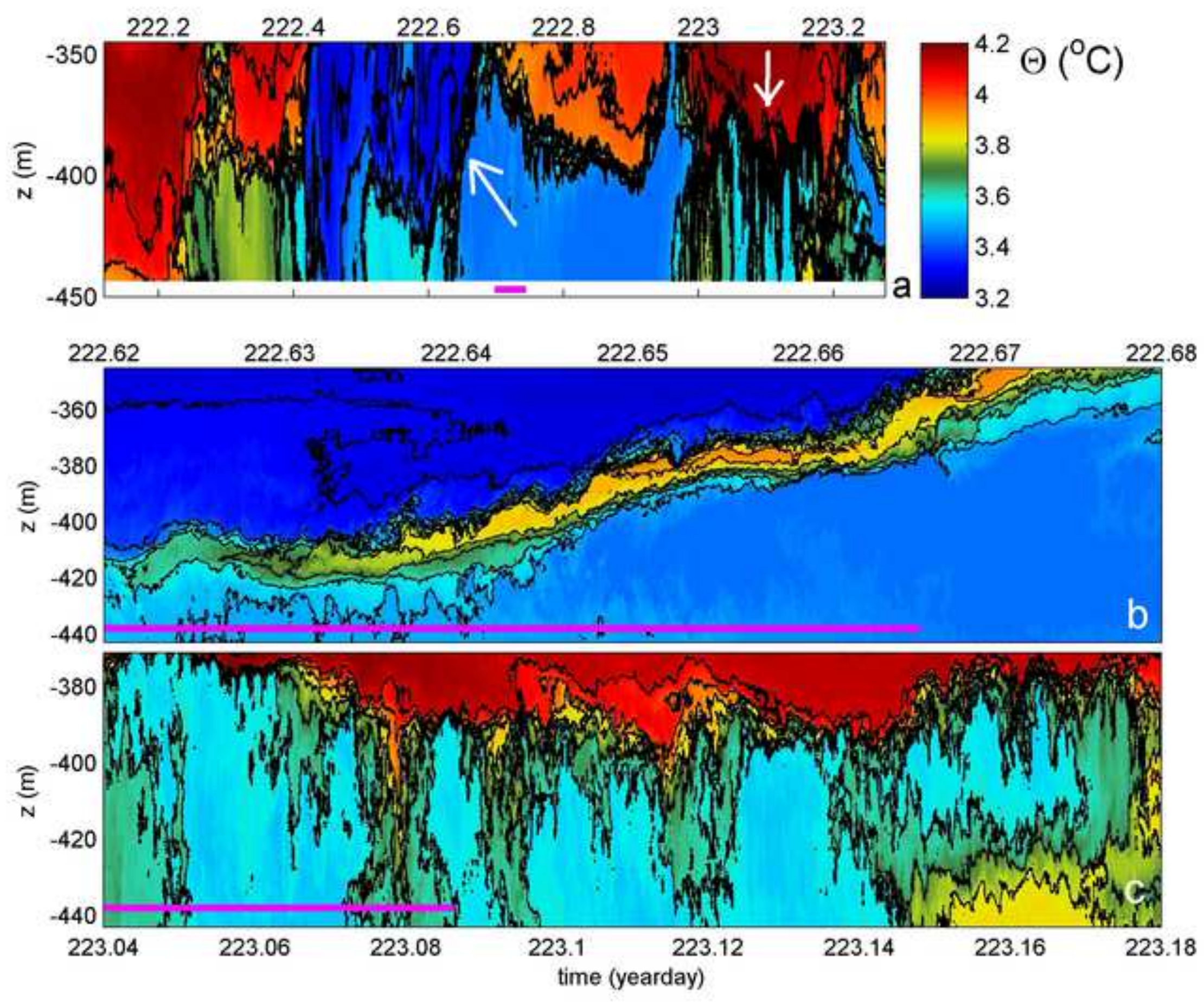

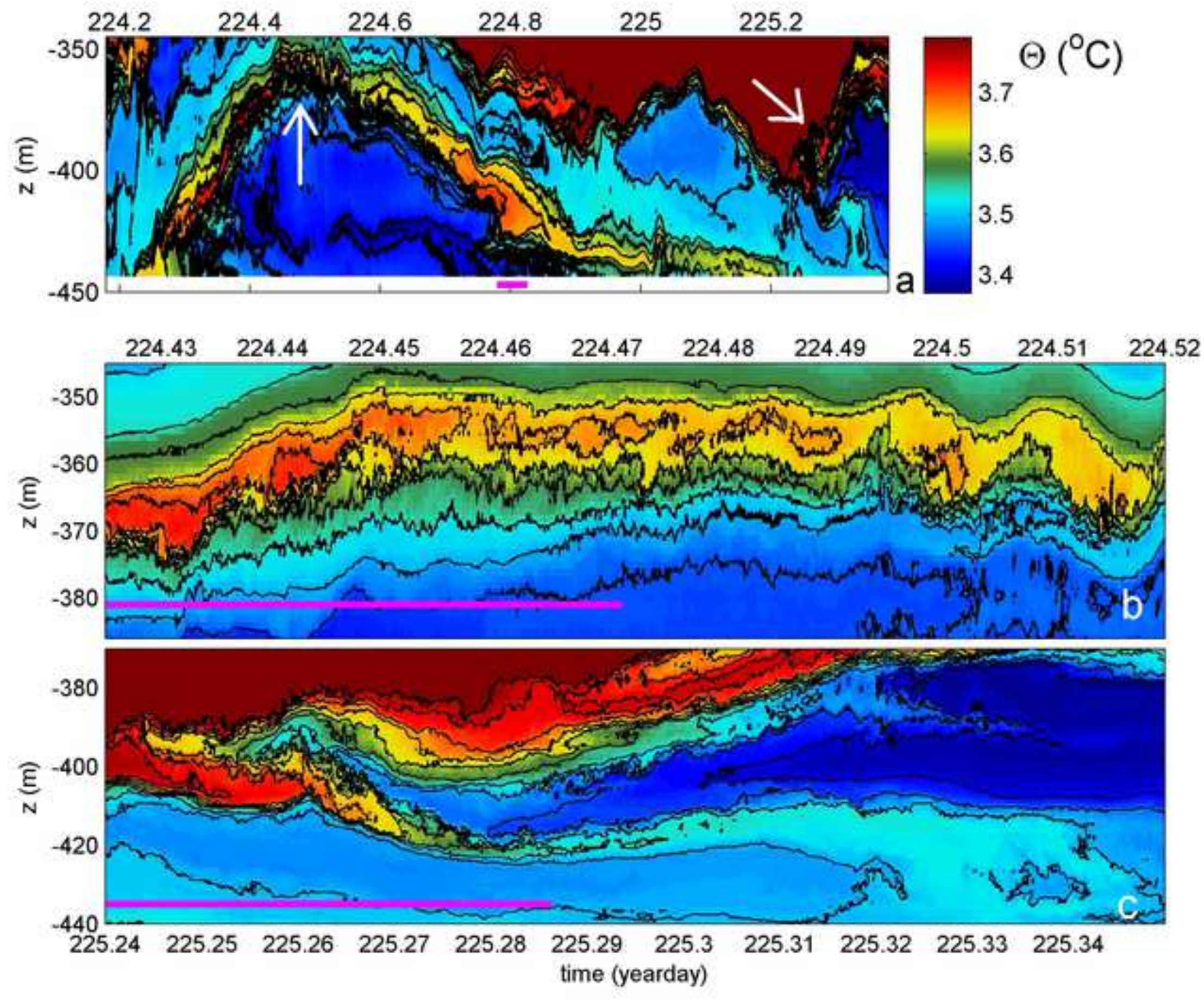

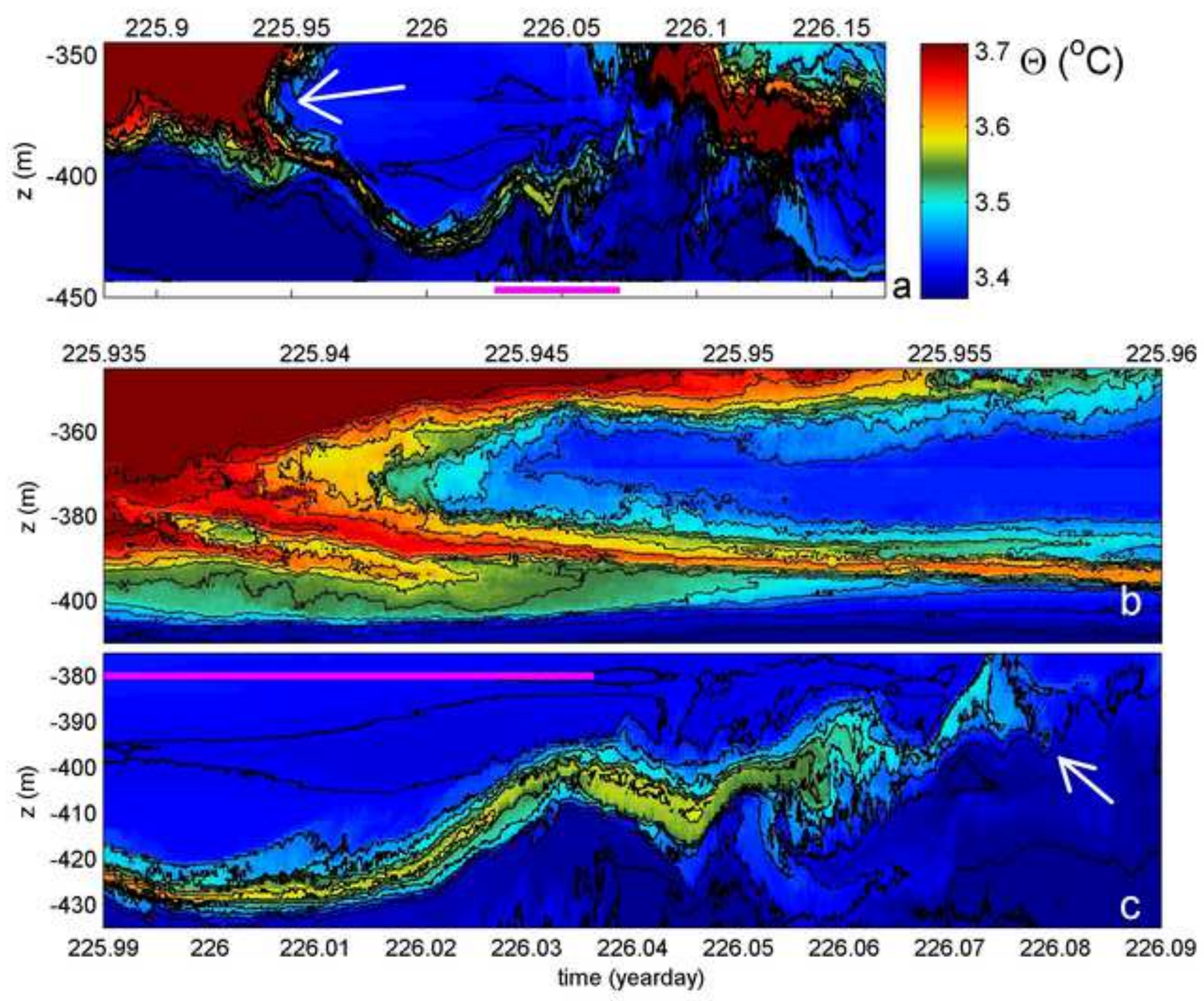


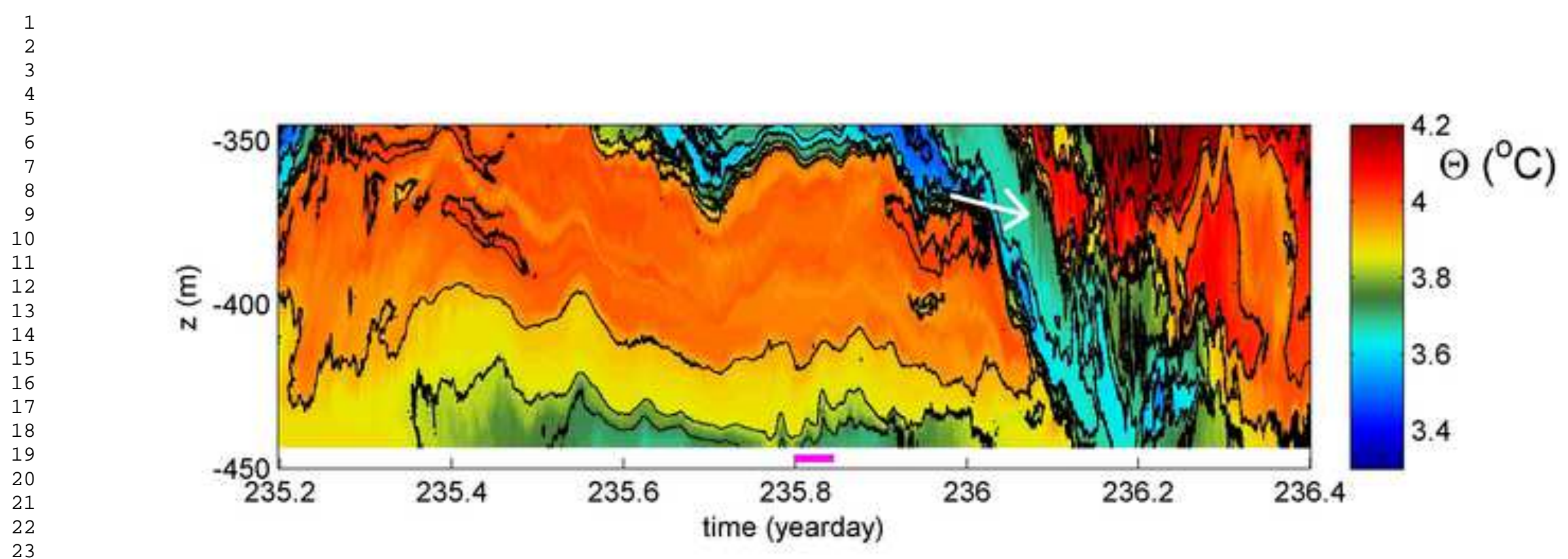



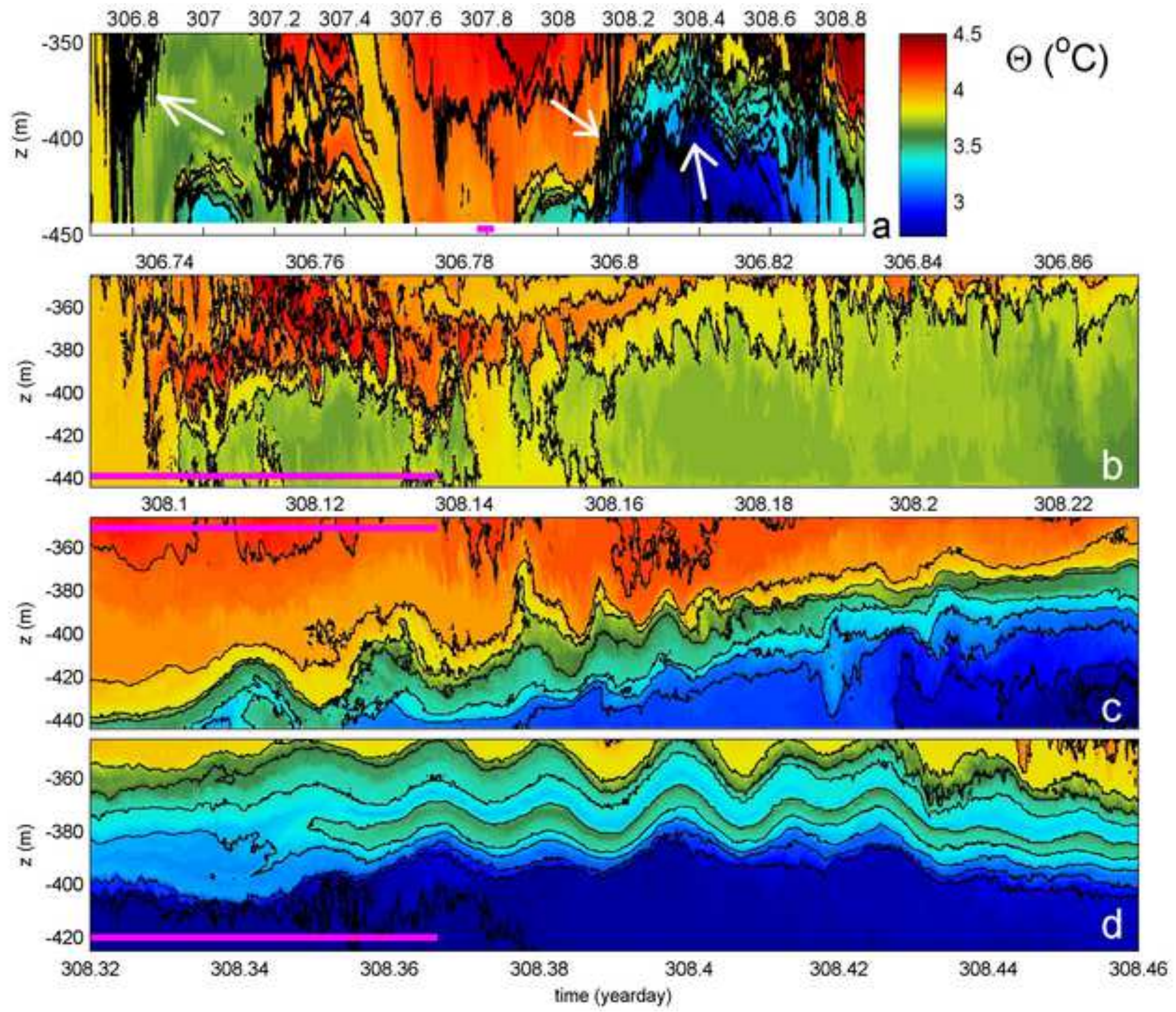


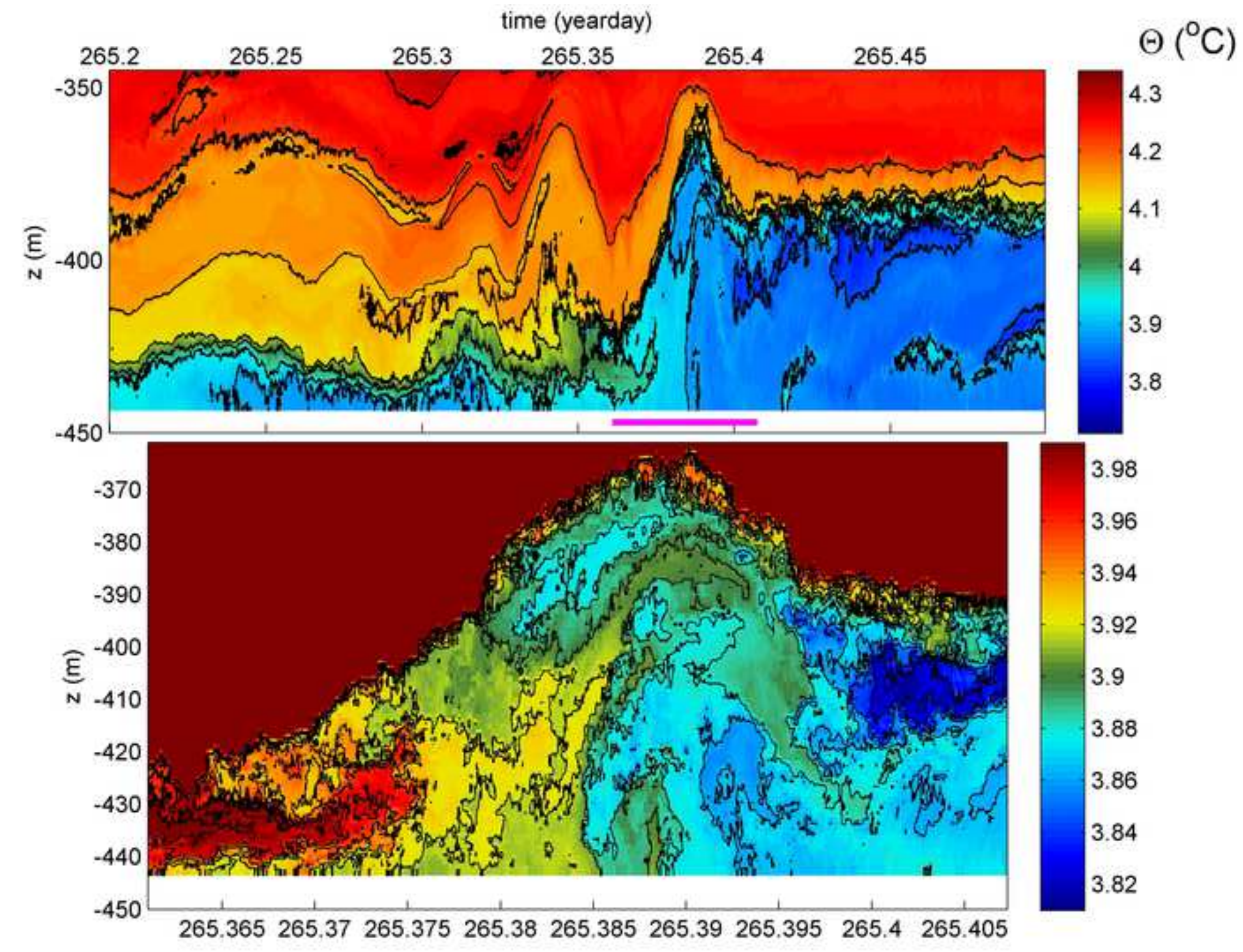

